\title{
EVALUATION OF GASTROPROTECTIVE POTENTIAL OF CAJANUS CAJAN SEEDS EXTRACT ON ETHANOL-INDUCED GASTRIC ULCER IN ALBINO RATS
}

\author{
C. AZUBUIKE NKIRUKA*, B. AMARA UDEMBA
}

Department of Medical Laboratory Sciences, Faculty of Health Sciences and Technology, College of Medicine, University of Nigeria, Enugu Campus, Nigeria. Email: nkiruka.azubike@unn.edu.ng

Received: 03 December 2021, Revised and Accepted: 14 January 2021

\section{ABSTRACT}

Objective: The present study was undertaken to evaluate the gastroprotective potential of Cajanus cajan seed aqueous extract (CCSE) on experimentally induced gastric ulcer in albino rats.

Methods: Preliminary acute toxicity study was conducted to determine the oral median lethal dose $\left(\mathrm{LD}_{50}\right)$. Twenty (20) male rats divided into five groups (A-E) of four animals each were used. Groups A (normal control) and B (ulcer model) received $10 \mathrm{ml} / \mathrm{kg}$ distilled water. Groups C, D, and E received cimetidine (100 mg/kg b.w intraperitoneally), $250 \mathrm{mg} / \mathrm{kg}$, and $500 \mathrm{mg} / \mathrm{kg}$ b.w of CCSE orally, respectively, once daily for 7 days. On day 8 , gastric ulcers were induced in Groups B-E using $80 \%$ ethanol ( $1 \mathrm{ml} / \mathrm{rat}$ ) before sacrifice. Ulcer indices were determined on excised stomach tissues before further processing for histological examination.

Results: The $\mathrm{LD}_{50}$ of CCSE is greater than $5 \mathrm{~g} / \mathrm{kg}$ b.w. Cimetidine and CCSE treatments showed statistically significant decrease (p<0.05) in ulcer indices compared to Group B (ulcer model). Histological features revealed noticeable preservation of the gastric mucosa in consistence with the macroscopical findings.

Conclusion: The present study revealed that $C$. cajan seed extract possesses gastroprotective properties against ethanol-induced gastric ulcers.

Keywords: Cajanus cajan, $\mathrm{LD}_{50}$, Stomach, Ulcer, Gastroprotection, Histopathology.

(c) 2021 The Authors. Published by Innovare Academic Sciences Pvt Ltd. This is an open access article under the CC BY license (http://creativecommons.org/ licenses/by/4.0/) DOI: http://dx.doi.org/10.22159/ajpcr.2021v14i12.43268. Journal homepage: https://innovareacademics.in/journals/index.php/ajpcr

\section{INTRODUCTION}

Peptic ulcer is among the common defects of the gastrointestinal walls and may manifest on the mucosal lining of the stomach or the small intestine [1]. Clinically, it presents as abdominal stress, most commonly in the upper part of the abdomen and epigastric region. Peptic ulcer occurs as a result of the imbalance between the endogenous aggressive factors and the intestinal defensive (cytoprotective) components [2,3]. The risk of developing gastric ulcers increases with continuous exposure of the gastric mucosa with aggressive factors such as stress, Helicobacter pylori infections, nonsteroidal anti-inflammatory drugs, nutritional deficiencies, smoking, and excessive consumption of ethanol [4].

Ethanol is a potent ulcerogenic agent commonly associated with multiple pathologies and it is administered orally to experimental animal models to challenge the gastric mucosa to produce lesions and ulcers $[5,6]$. The main therapeutic target of peptic ulcer is by employment of $\mathrm{H} 2$-blockers (cimetidine, ranitidine, and famotidine) or proton-pump antagonists (omeprazole and lansoprazole) which decrease gastric acid secretions, whereas sucralfate, carbenoxolone, and like drugs enhance mucosal defenses. In recent times, peptic ulcer treatment is faced with major drawbacks which pose a great concern and this is because of the problems associated with their severe side effects and limited efficacy. Thus, the search for safe and effective antiulcer agents is needed. Medicinal plants have contributed tremendously in the maintenance of health and management of diseases worldwide [7]. Extracts from plants have gained importance in pharmaceutical industries as source of new drugs which have shown promising results in combating various disease conditions including gastric ulcer. They have remained chief alternative for most people due to their availability, cheaper cost, and higher safety margin. Many medicinal plants with antiulcerogenic potential have been documented in scientific literature [8-10].
Cajanus cajan (L.) Millsp., commonly known as Pigeon pea, is a member of the family Fabaceae. Other common names are Congo pea, red gram, Gungo pea, and no eye pea [11]. Other local names in Nigeria are fio-fio (Igbo), ohele (Benin), otili (Yoruba), and olhene (Esan). It is one of the most commonly cultivated legumes in the tropics mainly for its edible seeds. India contributes nearly $90 \%$ of the total world production of pigeon pea [12]. In East Nigeria, it is extensively eaten in the form of porridge, and it is grown in Anambra, Enugu, and Benue. It is a rich source of proteins and highly nutritious [13]. It is a rich source of polyphenolic compounds $[12,14]$ and the presence of two globulins, cajanin and concajanin, has been described [15]. In Chinese traditional medicine, it is used for pain relief and as a sedative. It is also used for the treatment of malaria, bedsores, wounds, hepatitis, measles, diabetes, skin irritations, diabetes, dysentery, jaundice, for stabilizing menstrual period and expelling bladder stones [16-18]. Pharmacological activities attributed to the plant parts include antibacterial [19], antihelminthic [20], hepatoprotective [21-23], anticancer [24], memory impairment protection [25], anti-inflammatory, antioxidant, and antihyperglycemic [26,27] activities. Although many pharmacological activities of $C$. cajan seeds have been demonstrated, to our knowledge, there is no scientific report on antiulcerogenic activities. This study, therefore, was carried out to determine the effect of pretreatment with C. cajan aqueous seed extract (CCSE) on ethanol-induced gastric ulcer in rats.

\section{METHODS}

\section{Drugs and chemicals}

Ethanol (80\%) used for the induction of ulcers was procured from Sigma-Aldrich (St. Louis, MO, USA). Cimetidine (Caspian Tamin Pharmaceutical Co., Iran) was acquired from a local pharmaceutical store. All other solvents and reagents which were purchased from local sources were of analytical grade. 
Plant collection and authentication

Five hundred grams ( $500 \mathrm{~g}$ ) of the dried seeds of $C$. cajan were bought from New market, Enugu State, Nigeria, in the month of February 2015. A sample of the seed was authenticated by Mr. Felix Nwafor of the International Centre for Ethnomedicine and Drug Development (INTERCEDD), Nsukka as C. cajan (L) Millsp. with voucher number INTERCEDD/827.

\section{Extraction}

The seeds of $C$. cajan were grinded in their dry state using a gasoline milling machine. About $100 \mathrm{~g}$ of the fine powder was allowed to macerate in $0.4 \mathrm{~L}$ of distilled water and left for $12 \mathrm{~h}$. The mixture was homogenized intermittently by stirring and eventually sieved using a muslin cloth. The filtrate obtained was stored at $4^{\circ} \mathrm{C}$ in a refrigerator in a leak proof container until required. The concentration of the filtrate (aqueous extract [AE]) was determined by evaporating $2 \mathrm{ml}$ of the extract in a crucible of known weight in an oven (Gallenkamp, UK) to dryness. The crucible containing the residue was allowed to cool and then weighed. The weight of the extract (residue) was obtained by subtracting the initial weight of the crucible from the weight of the crucible containing the extract. The extractive value of the $\mathrm{AE}$ was $155 \mathrm{mg} / \mathrm{ml}$.

\section{Animal housing}

Twenty male Wistar rats aged 2-3 months old, weighing between 90 and $130 \mathrm{~g}$, were used for this study. They were obtained from the Department of Physiology, University of Nigeria, Enugu Campus. The rats were housed under standard conditions of $12 \mathrm{~h}$ light/dark cycle, humidity and temperature $\left(25 \pm 2^{\circ} \mathrm{C}\right)$. They were fed with standard rat pellets (Guinea feed ${ }^{\circledR}$ Nigeria Plc) and clean water ad libitum, kept in stainless steel wire mesh cages, and acclimatized for 1 week before commencement of the studies. Due care and diligence were observed in animal handling in accordance with the institutional and international standard guidelines for the care and use of laboratory animals in scientific research. The Institutional Animal Welfare and Ethics Committee approved all the experimental procedures carried out.

\section{Acute toxicity testing}

The acute toxicity testing of the crude extract was conducted to determine the oral lethal median dose $\left(\mathrm{LD}_{50}\right.$ determination) using the variation method described by Lorke [28] with slight modification. The acute toxicity experiment was done in two stages. Three groups of three rats each fasted overnight were kept under laboratory conditions and allowed free access to water. CCSE at concentrations of $1000 \mathrm{mg} / \mathrm{kg}$, $2000 \mathrm{mg} / \mathrm{kg}$, and $5000 \mathrm{mg} / \mathrm{kg}$ was administered once daily through an oral cannula to the three groups, respectively, and observed for $24 \mathrm{~h}$ for signs of toxicity such as depression, diarrhea, anorexia, sluggishness, paleness of eyes, and even mortality.

\section{Experimental design and conduct}

The animals were divided into five groups (A-E) of four rats each. Rats in Groups A (normal control) and B (ulcer model) received $10 \mathrm{ml} / \mathrm{kg}$ distilled water while those in Groups $\mathrm{C}$, D, and $\mathrm{E}$ received cimetidine (100 mg/kg b.w intraperitoneally), $250 \mathrm{mg} / \mathrm{kg} \mathrm{b.w} \mathrm{of} \mathrm{CCSE,} \mathrm{and}$ $500 \mathrm{mg} / \mathrm{kg}$ b.w of CCSE orally, respectively, once daily for 7 days.

\section{Experimental ulcer induction}

Induction of ulcer in the rats was achieved by oral administration of ethanol. After the last drug treatment on day 7, all animals were fasted for $24 \mathrm{~h}$ but were given water ad libitum. On day 8 , drug treatments were performed as usual and after $30 \mathrm{~min}$, rats in all groups were treated with $80 \%$ ethanol ( $1 \mathrm{ml} / \mathrm{rat}$ ) orally through an orogastric tube. One hour later, the rats were sacrificed under mild chloroform anesthesia and the stomachs of all the animals were excised and carefully cut along the line of greater curvature to expose the inner mucosa. The stomachs' contents were then washed off using physiological saline.

\section{Macroscopical examination}

Gastric mucosa lesions were observed using a hand magnifying lens $(\times 10)$ [29] and the severity was scored 0-4 using an arbitrary scale as described by MacAllister et al. [30] but with slight modification as follows: $0,0.5,1,2,3$, and 4 for no lesion, hyperemia, one or two lesions, multiple lesions with variable severity, very severe lesions, and mucosa full of lesions with active hyperemia, respectively. The ulcer index (UI) for each rat was determined by dividing the total of ulcer scores by 10 . However, the percentage ulcer inhibition was determined as follows:

$\frac{\mathrm{UI}(\text { control })-\mathrm{UI}(\text { treated })}{\mathrm{UI}(\text { control })} \times 100$

The gastric mucosa was then photographed and the excised organ (stomach) fixed with 10\% formalin for further histological processing.

\section{Tissue processing}

Histological processing of the tissues was performed using the paraffin wax embedding technique for light microscopy. The excised stomach tissues were subjected to different stages of processing including: Dehydration, dealcoholization/clearing, and wax impregnation using an automatic tissue processor. The wax impregnated tissues were embedded in the tissue cassettes with paraffin wax and thereafter mounted on a rotary microtome (Hertz 150, Cambridge model) for microtomy. Tissue sections of $5 \mu \mathrm{m}$ thickness were cut, floated on water bath, and picked using frosted end slides which have been albuminized to enhance adherence of the sections. Furthermore, the sections were stained for the demonstration of general tissue architecture according to the hematoxylin and eosin ( $\mathrm{H}$ and $\mathrm{E}$ ) staining technique as described by Baker et al. [31].

\section{Microscopical examination}

The tissue sections were examined using an Olympus ${ }^{\circledR}$ binocular microscope with an in-built lighting system. Areas of interest were photographed using an AmScope ${ }^{\circledR}$ digital microscope eyepiece camera.

\section{Statistical analysis}

Data obtained in this study were analyzed using the Statistical Package for the Social Sciences version 23.0. Data were expressed as mean \pm standard error of mean (SEM) and one-way analysis of variance (ANOVA) and the Dunnett's test were adopted to determine the differences among the groups. The level of significance was considered at $\mathrm{p}<0.05$.

\section{RESULTS}

The highest UI of $3.25 \pm 0.48$ was recorded in the ulcer model group, whereas statistically significant $(p<0.05)$ lower ulcer indices were observed in groups treated with cimetidine, 250 , and $500 \mathrm{mg} / \mathrm{kg}$ b.wt of CCSE (Table 1). The highest value for calculated percentage inhibition was $88 \%$ for $500 \mathrm{mg} / \mathrm{kg}$ CCSE followed by cimetidine $(76.92 \%)$ and $250 \mathrm{mg} / \mathrm{kg}$ CCSE (53.85\%).

Values are expressed as Mean \pm SEM $*$ and $\#=p<0.05$ when compared with ulcer model and cimetidine groups, respectively. CCSE - C. cajan aqueous seed extract.

Fig. 1 shows the gross appearance of the excised stomach tissues. Stomach of normal control rats showed intact gastric mucosa (1a),

Table 1: Effect of pre-treatment with aqueous extract of $C$. cajan on UI and percentage inhibition in ethanol-induced gastric ulcer in rats

\begin{tabular}{lll}
\hline Group & UI & Percentage inhibition (\%) \\
\hline Ulcer model & $3.25 \pm 0.48^{\#}$ & - \\
Cimetidine & $0.75 \pm 0.48^{*}$ & 76.92 \\
CCSE $(250 \mathrm{mg} / \mathrm{kg})$ & $1.50 \pm 0.29^{*}$ & 53.85 \\
CCSE $(500 \mathrm{mg} / \mathrm{kg})$ & $0.38 \pm 0.24^{*}$ & 88.31 \\
F-ratio & 10.878 & \\
p-value & 0.001 & \\
\hline
\end{tabular}



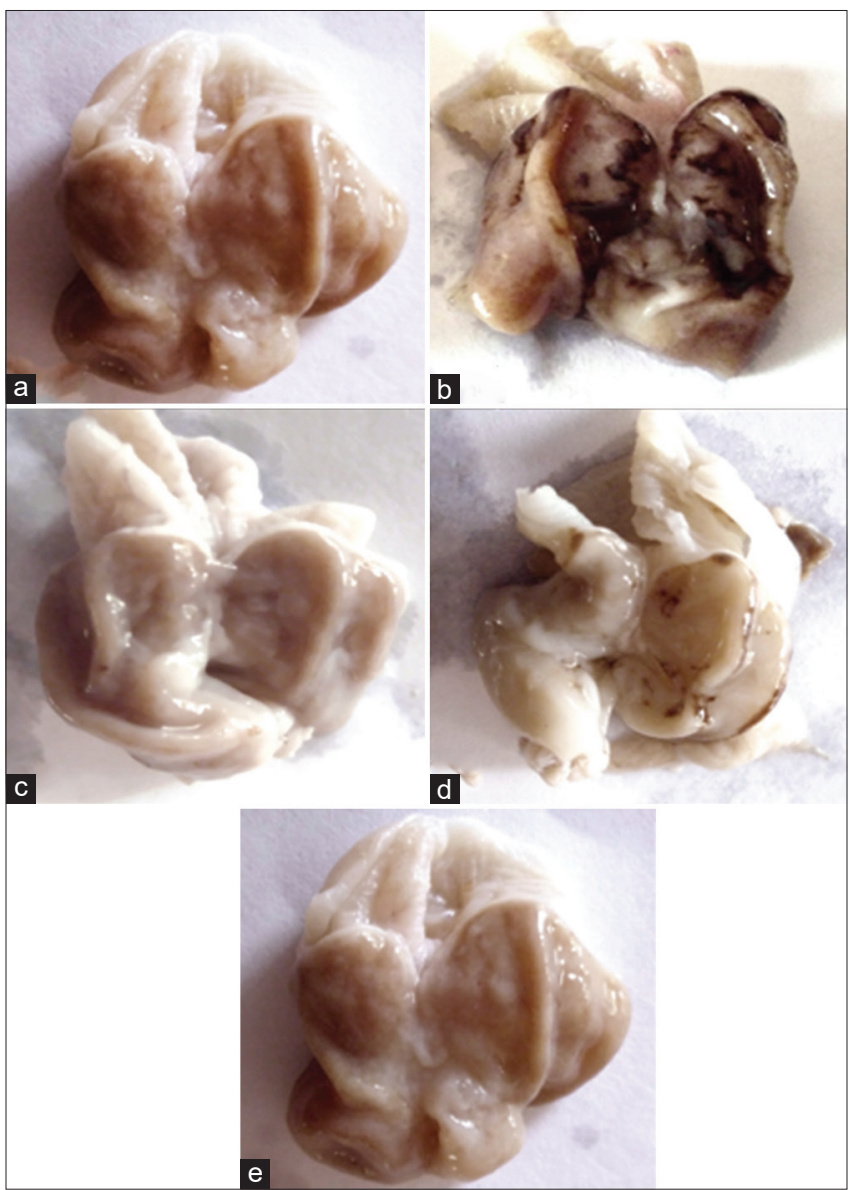

Fig. 1: Photomacrographs showing the gross anatomical appearance of the excised stomach tissues of rats in control (a) and all treatment groups (b-e) (a): Group A (control) showing normal features of the gastric mucosa; (b): Group B ( $1 \mathrm{ml} / \mathrm{kg} \mathrm{80 \%}$ ethanol only - ulcer model) showing severe hemorrhagic streaks and petechial lesions on the stomach mucosa; (c): Group C (100 mg/kg cimetidine) showing good preservation of the stomach mucosa; (d): Group D (250 mg/kg C. cajan extract) showing very mild petechial lesions; (e): Group E (500 mg/kg C. cajan extract) showing markedly preserved gastric mucosa

however, in ulcer model group, oral administration of ethanol-induced intense gastric mucosal damage producing hemorrhagic streaks and ulcers (1b). Treatment with $250 \mathrm{mg} / \mathrm{kg}$ and $500 \mathrm{mg} / \mathrm{kg}$ body weight of CCSE produced markedly reduced gastric mucosal damage $1 \mathrm{~d}$ and $1 \mathrm{e}$, respectively). When compared with the reference drug, cimetidine (1c) and $500 \mathrm{mg} / \mathrm{kg}$ CCSE treatment were found to exert similar effects of gastric mucosal preservation.

Microscopical examination of the stomach sections as shown in Fig. 2 also revealed the same pattern of effects consistent with the gross studies. Severe mucosal ulcerations in ulcer model group (2b) were noted while marked preservation of the gastric mucosa was observed in groups treated with cimetidine and CCSE (Figs. 2c-e).

\section{DISCUSSION}

The present study was undertaken to determine the effect of pretreatment with $C$. cajan seed extract (CCSE) on ethanol-induced gastric ulcer. Preliminary determination of the oral median lethal dose $\left(\mathrm{LD}_{50}\right)$ of the extract showed that the plant seed is non-toxic since the value is beyond $5 \mathrm{~g} / \mathrm{kg}$ b.wt in rats. At this dose, no obvious sign of toxicity and mortality was observed in the rats. Behavioral changes such as

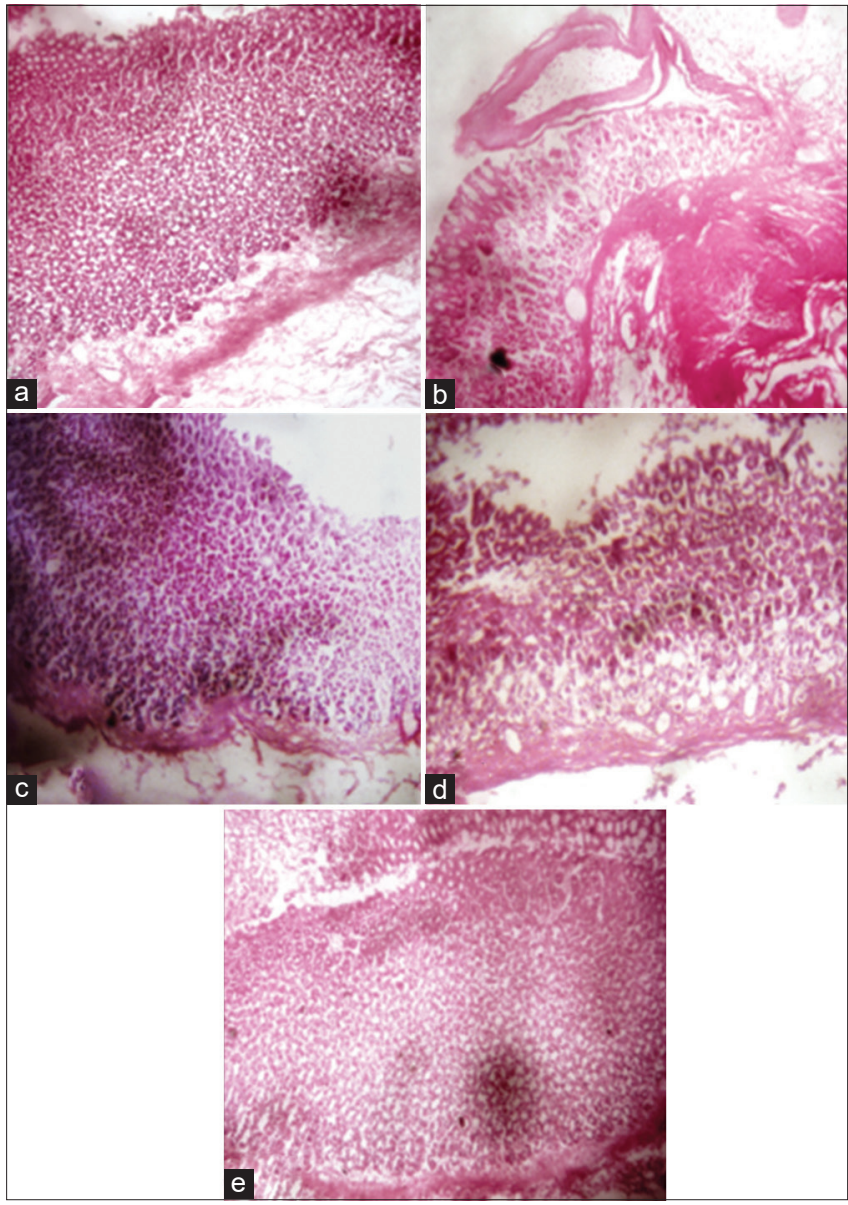

Fig. 2: Light photomicrographs of histological sections from stomach tissues of rats in control (a) all treatment groups (b-e)

[Stain: $\mathrm{H}$ and $\mathrm{E}: \times 100$ ]. (a): Group A (control) showing intact histoarchitecture of the gastric mucosa; (b): Group B (1 ml/kg $80 \%$ ethanol only - ulcer model) showing evidence of eroded superficial cells and gastric glands degeneration; (c): Group C

$(100 \mathrm{mg} / \mathrm{kg}$ cimetidine) showing mildly eroded superficial cells; (d): Group D (250 mg/kg C. cajan extract) showing mild superficial cells erosion and glandular degeneration; (e): Group E

$(500 \mathrm{mg} / \mathrm{kg}$ C. cajan extract) showing markedly preserved gastric mucosa

respiratory distress, restlessness, abnormal locomotion, and irritation over a period of 2 days were not observed. Hence, it can be inferred that the extract is safe for oral consumption up to the dose of $5 \mathrm{~g} / \mathrm{kg}$ body weight as previously described [32].

On oral administration of $80 \%$ ethanolat a dose of $1 \mathrm{ml} / \mathrm{rat}$, intense gastric mucosal damage observed as hemorrhagic streaks, petechial lesions and ulcers were produced in the rats used for the present study. Ethanol acts directly on the epithelial lining of the gastric mucosa inducing lesions by reducing defensive factors such as mucus production and secretion of bicarbonate $[9,33]$. High concentration of ethanol, being noxious to the gastric mucosa, provokes microvascular alterations within a minute of its administration [34]. Typical characteristic lesions produced by alcohol ingestion include linear hemorrhagic streaks, gastric mucosal epithelial cell loss, inflammatory cellular infiltration, and extensive submucosal edema $[35,36]$. The pathogenesis of ethanol-induced gastric mucosal injury is the disruption of the equilibrium existing between the aggressive factors and defensive factors which occur through various mediators including reactive oxygen species $[2,3,37]$. Consequently, any agent which has the ability to restore the equilibrium either by reducing gastric acid secretion or by enhancing the activity of the cytoprotective agents could serve as an antiulcer agent. 
In this study, pre-treatment with cimetidine (standard anti-ulcer drug) prevented the ethanol-induced lesions in the gastric mucosa of the treated rats. Cimetidine is a $\mathrm{H}_{2}$-receptor antagonist and is a well-known anti-ulcer drug which establishes its activity by blocking the effect of histamine, pentagastrin, and carbol-induced hyperacidity. It is also a conventional anti-secretory drug (gastric acid pump inhibitor). Similarly, pre-treatment with CCSE showed the ability to significantly reduce the severity of ethanol-induced hemorrhages, ulcerations, and presence of petechial lesions in a dose-dependent manner. It appeared that CCSE prevented the ethanol-induced gastric damage by an ability to protect the stomach mucosal layer from the harsh effects posed by ethanol. The mechanism for the observed cytoprotective effect may be mediated either by a decline in aggressive factors (pepsin and acid) or by an increase in mucosal resistance. Since $C$. cajan seeds have been shown to have alkaloids, flavonoids, saponins, and tannins, among other phytochemical constituents [38,39], its protective effects may be attributed to one or a combination of these phytochemicals. Plants rich in these phytochemicals been shown to have anti-ulcerative and gastroprotective properties $[40,41]$.

\section{CONCLUSION}

The present study demonstrates that $C$. cajan seeds possess dose-dependent gastroprotective effects against ethanol-induced gastric hemorrhagic injuries in albino rats. Thus, $C$. cajan is a promising anti-ulcer agent that can be used for the treatment of gastric ulcer.

\section{AUTHORS' CONTRIBUTIONS}

Azubuike $\mathrm{N}$ served as a supervisor, conceptualized the research, designed the protocol, assisted in data collection, data analysis, and final manuscript writing. Udemba A wrote the initial draft of the manuscript, reviewed literature, and also involved in collection of data. Authors read and approved the final manuscript.

\section{CONFLICTS OF INTEREST}

The authors declare no conflicts of interest.

\section{AUTHORS' FUNDING}

The authors received no external funding.

\section{REFERENCES}

1. Dhasan PB, Jegadeesan M, Kavimani S. Antiulcer activity of aqueous extract of fruits of Momordica cymbalaria Hook f. in Wistar rats. Pharmacogn Res 2010;2:58-61.

2. Raju D, Ilango K, Chitra V, Ashish K. Evaluation of Anti-ulcer activity of methanolic extract of Terminalia chebula fruits in experimental rats. J Pharm Sci Res 2009;1:101-7.

3. Wasman SQ, Mahmood AA, Salehhuddin H, Zahra AA, Salmah I. Cytoprotective activities of Polygonum minus aqueous leaf extract on ethanol-induced gastric ulcer in rats. J Med Plants Res 2010;4:2658-65.

4. Bandyopadhyay D, Biswas K, Reiter RJ, Banerjee RK. Gastric toxicity and mucosal ulceration induced by oxygen-derived reactive species: Protection by melatonin. Curr Mol Med 2001;1:501-13.

5. Alimi H, Hfaiedh N, Bouoni Z, Sakly M, Rhouma KB. Evaluation of antioxidant and antiulcerogenic activities of Opuntia ficus indica f. inermis flowers extract in rats. Environ Toxicol Pharmacol 2011;32:406-16.

6. Guzmán-Gómez O, García-Rodríguez RV, Quevedo-Corona L, Pérez-Pastén-Borja R, Rivero-Ramírez NL, Ríos-Castro E, et al. Amelioration of ethanol-induced gastric ulcers in rats pretreated with phycobiliproteins of Arthrospira (Spirulina) Maxima. Nutrients 2018;10:763.

7. de Lira Mota KS, Dias GE, Pinto ME, Luiz-Ferreira Â, Souza-Brito AR, Hiruma-Lima CA, et al. Flavonoids with gastroprotective activity. Molecules 2009;14:979-1012.

8. Abdulla MA, Al-Bayaty FH, Younis LT, Hassan MA. Anti-ulcer activity of Centella asiatica leaf extract against ethanol-induced gastric mucosal injury in rats. J Med Plants Res 2010;4:1253-9.

9. AlRashdi AS, Salama SM, Alkiyumi SS, Abdulla MA, Hadi AH, Abdelwahab SI, et al. Mechanisms of gastroprotective effects of ethanolic leaf extract of Jasminum sambac against $\mathrm{HCl} /$ ethanolinduced gastric mucosal injury in rats. Evid Based Complement Altern Med 2012;2012:786426.

10. Steven OO, Uwadiegwu AP, Chinonyelum AN, Chukwu ND, Obianuju OA, Kingsley UI, et al. Preliminary studies on the anti-ulcer potentials of Vitex doniana crude extracts on experimental rat model of ethanol induced gastric ulcer. Asian Pac J Trop Dis 2016;6:736-40.

11. Wu N, Fu K, Fu YJ, Zu YG, Chang FR, Chen YH, et al. Antioxidant activities of extracts and main components of pigeonpea [Cajanus cajan (L.) Millsp.] leaves. Molecules 2009;14:1032-43.

12. Pal D, Mishra P, Sachan N, Ghosh AK. Biological activities and medicinal properties of Cajanus cajan (L) Millsp. J Adv Pharm Technol Res 2011;2:207-14.

13. Varshney RK, Penmetsa RV, Dutta S, Kulwal PL, Saxena RK, Datta S, et al. Pigeonpea genomics initiative (PGI): An international effort to improve crop productivity of pigeonpea (Cajanus cajan L.). Mol Breed 2010;26:393-408.

14. Sahu M, Vermaand D, Harris KK. Phytochemicalanalysis of the leaf, stem and seed extracts of Cajanus cajan L (Dicotyledoneae: Fabaceae). World J Pharm Pharm Sci 2014;3:694-733.

15. Ambasta SP. The useful plants in India. In: National Institute of Science Communication. $4^{\text {th }}$ ed. New Delhi, India: National Institute of Science Communication; 2004. p. 5.

16. Aiyeloja AA, Bello OA. Ethnobotanical potentials of common herbs in Nigeria: A case study of Enugu state. Educ Res Rev 2006;1:16-22.

17. $\mathrm{Zu} \mathrm{YG,} \mathrm{Liu} \mathrm{XL,} \mathrm{Fu} \mathrm{YJ,} \mathrm{Wu} \mathrm{N,} \mathrm{Kong} \mathrm{Y,} \mathrm{Wink} \mathrm{M.} \mathrm{Chemical}$ composition of the SFE- $\mathrm{CO}_{2}$ extracts from Cajanus cajan (L.) Huth and their antimicrobial activity in vitro and in vivo. Phytomedicine 2010; $17: 1095-101$

18. Dolui AK, Sengupta R. Antihyperglycemic effect of different solvent extracts of leaves of Cajanus cajan and HPLC profile of the active extracts. Asian J Pharm Clin Res 2012;5:116-9.

19. Siyabonga SJ, Ayanda M, Sydney MT, Oluwole SF. Comparative evaluation of antibacterial activity of induced and non-induced Cajanus cajan seed extract against selected gastrointestinal tract bacteria. Afr J Microbiol Res 2016;10:319-23.

20. Siddhartha S, Archana M, Jinu J, Pradeep M. Anthelmintic potential of Andrographis paniculata, Cajanus cajan and Silybum marianum. Pharmacogn J 2009;1:243.

21. Kundu R, Dasgupta S, Biswas A, Bhattacharya A, Pal BC, Bandyopadhyay D, et al. Cajanus cajan Linn. (Leguminosae) prevents alcohol-induced rat liver damage and augments cytoprotective function. J Ethnopharmacol 2008;118:440-7.

22. Ahsan R, Islam KM, Musaddik A, Haque E. Hepatoprotective activity of methanol extract of some medicinal plants against carbon tetrachloride induced hepatotoxicity in albino rats. Glob J Pharmacol 2009;3:116-22.

23. Iweala EE, Evbakhavbokun WO, Maduagwu EN. Antioxidant and hepatoprotective effect of Cajanus cajan in N-nitrosodiethylamineinduced liver damage. Sci Pharm 2019;87:24.

24. Luo M, Liu X, Zu Y, Fu Y, Zhang S, Yao L, et al. Cajanol, a novel anticancer agent from Pigeonpea [Cajanus cajan (L.) Millsp.] roots, induces apoptosis in human breast cancer cells through a ROS-mediated mitochondrial pathway. Chem Biol Interact 2010;188:151-60.

25. Ahmad L, Mujahid M, Mishra A, Rahman MA. Protective role of hydroalcoholic extract of Cajanus cajan Linn leaves against memory impairment in sleep deprived experimental rats. J Ayurveda Integr Med 2020;11:471-7.

26. Hassan EM, Matloub AA, Aboutabl ME, Ibrahim NA, Mohamed SM. Assessment of anti-inflammatory, antinociceptive, immunomodulatory, and antioxidant activities of Cajanus cajan L. seeds cultivated in Egypt and its phytochemical composition. Pharm Biol 2016;54:1380-91.

27. Uchegbu NN, Ishiwu CN. Germinated Pigeon Pea (Cajanus cajan): A novel diet for lowering oxidative stress and hyperglycemia. Food Sci Nutr 2016;4:772-7.

28. Lorke D. A new approach to practical acute toxicity testing. Arch Toxicol 1983;54:275-87.

29. Bharti S, Wahane VD, Kumar VL. Protective effect of Calotropis procera latex extracts on experimentally induced gastric ulcers in rat. J Ethnopharmacol 2010;127:440-4.

30. MacAllister CG, Andrews FM, Deegan E, Ruoff W, Olovson SG. A scoring system for gastric ulcers in the horse. Equine Vet $\mathrm{J}$ 1997;29:430-3.

31. Baker FJ, Silverton RE, Pallister CJ. Staining procedures. Introduction to Medical Laboratory Technology; 2001.

32. Timbrel JA. Principle of Biochemical Toxicology. $4^{\text {th }}$ ed. New York: Informa; 2009.

33. de Paula Ferreira M, Nishijima CM, Seito LN, Dokkedal AL, 
Lopes-Ferreira M, Di Stasi LC, et al. Gastroprotective effect of Cissus sicyoides (Vitaceae): Involvement of microcirculation, endogenous sulfhydryls and nitric oxide. J Ethnopharmacol 2008;117:170-4.

34. Trier JS, Szabo S, Allan CH. Ethanol-induced damage to mucosal capillaries of rat stomach: Ultrastructural features and effects of prostaglandin F2 $\beta$ and cysteamine. Gastroenterology 1987;92:13-22.

35. Arab HH, Salama SA, Omar HA, Arafa ES, Maghrabi IA. Diosmin protects against ethanol-induced gastric injury in rats: Novel anti-ulcer actions. PLoS One 2015;10:e 0122417.

36. Qin S, Yin J, Huang S, Lin J, Fang Z, Zhou Y, et al. Astragaloside IV protects ethanol-induced gastric mucosal injury by preventing mitochondrial oxidative stress and the activation of mitochondrial pathway apoptosis in rats. Front Pharmacol 2019;10:894.

37. Oates PJ, Hakkinen JP. Studies on the mechanism of ethanol-induced gastric damage in rats. Gastroenterology 1988;94:10-21.

38. Nanna RS, Banala M, Pamulaparthi A, Kurra A, Kagithoju S. Evaluation of phytochemicals and fluorescent analysis of seed and leaf extracts of Cajanus cajan L. Int J Pharm Sci Rev Res 2013;22:11-8.

39. Devi RR, Premalatha R, Saranya A. Comparative analysis of phytochemical constituents and antibacterial activity of leaf, seed and root extract of Cajanus cajan (L.) Mill sp. Int J Curr Microbiol Appl Sci 2016;5:485-94.

40. Sannomiya M, Fonseca VB, Da Silva MA, Rocha LR, Dos Santos LC, Hiruma-Lima CA, et al. Flavonoids and antiulcerogenic activity from Byrsonima crassa leaves extracts. J Ethnopharmacol 2005;97:1-6.

41. Sharifi-Rad M, Fokou PV, Sharopov F, Martorell M, Ademiluyi AO, Rajkovic J, et al. Antiulcer agents: From plant extracts to phytochemicals in healing promotion. Molecules 2018;23:1751. 